\title{
ARTIGO
}

DOI: $\underline{\text { http://dx.doi.org/10.20396/sss.v16i2.8651462 }}$

(cc) $\mathrm{Br}-\mathrm{NC}-\mathrm{SA}$

\section{REPRESENTAÇõES DE PROFISSIONAIS DA SAÚDE E ASSISTÊNCIA SOCIAL SOBRE A INTERSETORIALIDADE NA ÁREA DE ÁLCOOL E OUTRAS DROGAS}

\author{
SOCIAL REPRESENTATIONS OF HEALTH AND SOCIAL CARE PROFESSIONALS ABOUT
}

INTERSECTORIALITY ON ALCOHOL AND OTHER DRUGS FIELD

\author{
Ingrid de Assis Camilo Cabral \\ Carla Dalbosco ${ }^{2}$
}

\section{RESUMO}

As ações intersetoriais visam romper com a fragmentação das políticas públicas, mas identifica-se que alguns equipamentos do SUS e SUAS situados no mesmo espaço geográfico podem ser ofertados isoladamente, dificultando a integralidade do atendimento. No caso do uso abusivo de substâncias psicoativas, a complexidade inerente ao tema prejudica o indivíduo em diversas áreas da vida, requerendo respostas integradas e abrangentes do poder público. Visando contribuir para minimizar entraves na execução da prática intersetorial entre a saúde e a assistência social, o objetivo deste estudo foi identificar representações sociais de gestores e profissionais sobre a intersetorialidade na área de drogas no município de Resende - RJ. Por meio de uma metodologia qualitativa, foram realizadas oito entrevistas com gestores e dois grupos focais com quatorze representantes das equipes técnicas do município. Como metodologia de análise, foram construídas categorias com auxílio do software NVIVO para posterior análise temática. Os resultados indicaram dificuldades no estabelecimento de protocolos e que muitos profissionais da rede desconhecem a função de cada política setorial. A intersetorialidade é vista como viabilizadora de direitos, mas os profissionais da Secretaria de Assistência Social sentem-se pouco valorizados pelo setor saúde, que desconhece a atuação da política assistencial. Destaca-se a importância de romper a fragmentação para ações conjuntas de cuidado aos usuários, já que os mesmos sujeitos transitam entre as áreas e qualquer entrave de acesso pode refletir negativamente no tratamento. Espera-se contribuir para melhorar os fluxos da rede de acolhimento em nível local, fortalecendo a reinserção social de usuários de álcool e outras drogas.

PALAVRAS-CHAVE: Intersetorialidade. Drogas. Políticas públicas. Seguridade Social.

\footnotetext{
${ }^{1}$ Assistente Social, Mestre em Prevenção e Assistência a Usuários de Álcool e Outras Drogas. Prefeitura Municipal de Resende, RJ.

${ }^{2}$ Doutora em Psicologia Clínica e Cultura, Vice-coordenadora do Programa de Mestrado Profissional em Álcool e Outras Drogas do Hospital de Clínicas de Porto Alegre, HCPA/UFRGS.

Serv. Soc. \& Saúde, Campinas, SP v.16, n. 2 (24), p. 189-210, jul./dez. 2017 E-ISSN 2446-5992
} 


\begin{abstract}
The Intersectoriality aims to break the fragmentation of public policies, but it is identified that some Public Health and Social Assistance equipments located in the same geographical area, can be offered in isolation, hindering the integrality of the service. The complexity of psychoactive substances requires comprehensive responses of the government and integrated actions. The aim was to identify social representations of managers and professionals on the intersectional approach on drugs in a municipality, in order to contribute to minimize obstacles in the execution of intersectional practice between health and social assistance. Through a qualitative methodology, there were 8 interviews with managers and two focus groups with 14 representatives of the technical staff of the two departments. As a methodology of analysis, categories were built using NVIVO software for thematic analysis. The results indicate that there are difficulties in establishing protocols and many professionals are unaware of the function of each policy. Intersectoriality is seen as enabling rights, but social care professionals feel little valued by the health sector, which is unaware of the actions of social care policy. It has to approach the sectors for joint actions because the same users move between health and social care and any obstacle can reflect negatively in the treatment process. It is hoped to contribute to improving the flows of the local level network, strengthening the social reinsertion of users of alcohol and other drugs.
\end{abstract}

KEYWORDS: Intersectoral collaboration. Drugs. Public Policy.

\title{
INTRODUÇÃOO
}

O uso de substâncias psicoativas adquiriu dimensões preocupantes nas últimas décadas, tornando-se um dos graves problemas de saúde pública enfrentados no Brasil e no mundo. Segundo dados do United Nations Office on Drugs and Crime (UNODC, 2016), um a cada 20 adultos, cerca de 250 milhões de pessoas entre 15 e 64 anos, fez uso de alguma droga em 2014. Estima-se que apenas um a cada seis indivíduos com transtorno por uso de substâncias em todo o mundo (4,5 milhões de pessoas) recebe o tratamento necessário, a um custo global de cerca de US\$ 35 bilhões por ano.

Uma das maiores dificuldades para a abordagem do tema reside no fato de que o consumo é visto ora como doença, ora como crime ou desvio social, gerando intervenções contraditórias que, muitas vezes, não consideram a complexidade envolvida. De modo geral, as políticas públicas carecem de melhor integração e, muitas vezes, apresentam barreiras de acesso, principalmente para aqueles usuários em situação de alta vulnerabilidade social. Entende-se que o enfrentamento deste fenômeno só poderá ser compreendido em sua totalidade por meio da construção de redes de atenção territorializadas e do diálogo entre diferentes perspectivas e políticas setoriais (ANDRADE, 2014, LAPORT; JUNQUEIRA, 2015; SARONI et al., 2016; TEIXEIRA et al., 2017), com destaque para as de Saúde e Assistência Social. 
O conceito de intersetorialidade é entendido como a articulação entre setores sociais distintos para enfrentar problemas complexos, unindo saberes, experiências e poderes diversos. A intersetorialidade engloba o planejamento conjunto de ações para alcançar efeito sinérgico, visando o desenvolvimento social e, em alguns casos, a superação da exclusão social (JUNQUEIRA, 2004; SCHUTZ; MIOTO, 2010). No caso da Seguridade Social, pode ser vista como uma nova forma de trabalhar, governar e construir políticas públicas, entendendo os usuários dessas políticas em sua totalidade, pois possibilita a superação da fragmentação do conhecimento (ROMAGNOLI, 2010).

A execução da intersetorialidade possui um desenvolvimento complexo, pois não há normatização específica para o seu direcionamento, planejamento, implantação e operacionalização. Traz, assim, alguns desafios, a exemplo: no campo governamental, os acordos e pactos políticos entre os atores envolvidos; no campo institucional, identificar a necessidade de criação de novos equipamentos ou adaptação dos anteriores; e, por fim, nos processos de trabalho, o olhar do técnico responsável pela execução da ação intersetorial em sua prática cotidiana (PEREIRA; TEIXEIRA, 2013).

Schutz e Mioto (2010) elucidam que a intersetorialidade pode ser pensada sobre três perspectivas: 1) complementaridade de setores, 2) prática e 3) princípio do trabalho com redes. A primeira refere-se a uma nova maneira de abordar as demandas da população, rompendo com a fragmentação das políticas a partir de ações integradas, com prioridades estabelecidas por necessidades reais. A segunda perspectiva refere-se à mobilização para uma ação prática, em que cada setor oferece sua expertise. Já a terceira, orienta a criação de redes intersetoriais que atendam a população em alta vulnerabilidade, envolvendo serviços públicos e sociedade civil organizada.

Como afirma Junqueira (2000), a intersetorialidade agrega a concepção de integração e equidade, sendo uma alternativa para tratar as necessidades sociais de um mesmo território por meio de um planejamento articulado das ações e serviços. Porém, o que identificamos no cotidiano de muitas cidades brasileiras é que, embora os serviços de saúde e assistência social direcionados à população usuária de drogas ocupem o mesmo espaço geográfico, são ofertados isoladamente por cada política pública. Este fato acaba por dificultar a integralidade do atendimento.

Cumpre lembrar que a legislação brasileira relativa ao consumo de drogas evoluiu muito em anos recentes, tendo como marco a lei $\mathrm{n}^{\circ} 11.343$ (BRASIL, 2006), que trouxe Serv. Soc. \& Saúde, Campinas, SP v.16, n. 2 (24), p. 189-210, jul./dez. 2017 E-ISSN 2446-5992 
elementos articulados de prevenção do uso, atenção e reinserção social dos usuários e dependentes de substâncias psicoativas, em conformidade com a Política Nacional sobre Drogas já vigente (BRASIL, 2010). Destaca-se ainda que, com o avanço na garantia dos direitos relativos à Saúde, Previdência e Assistência Social via a Seguridade Social, ficou assegurada uma rede de proteção ampliada (BOSCHETTI, 2003). Todavia, apesar das políticas de saúde e assistência social preconizarem a intersetorialidade como estratégia de ação, o SUS e o SUAS possuem objetivos de atenção diferenciados aos usuários dos serviços, com responsabilidades específicas, o que torna o desafio da integração ainda maior (MOTA et al., 2013). Focar apenas na alteração dos marcos legislativos não é suficiente, pois as ações precisam ser pensadas para além de planos e propostas. Para que as mudanças sejam implementadas no cotidiano dos serviços, é necessário criar no imaginário social uma nova representação da intersetorialidade, em oposição à superespecialização dos setores (MOTA; RONZANI, 2013; NASCIUTTI, 2006).

Tendo em vista que este tema ainda é pouco explorado no Brasil, esta pesquisa foi realizada com o objetivo de identificar concepções de gestores e profissionais da saúde e da assistência social sobre a intersetorialidade na área de drogas em um município brasileiro. Buscou-se, ainda, conhecer o contexto do município no tocante às políticas sobre drogas, as parcerias acionadas entre as áreas de Saúde e Assistência Social e investigar o potencial para a realização de ações conjuntas.

Como referencial teórico de base foi utilizada a teoria de representações sociais (MOSCOVICI, 2003), que busca entender como as pessoas de um determinado grupo explicam e representam o mundo e como compartilham desse conhecimento para constituírem uma realidade em comum (MOSCOVICI, 2003; OLIVEIRA, 2004; BANCHS, 2002). De acordo com Sêga (2000), o conceito de representação social se expressa na forma de compreensão da realidade cotidiana pelos indivíduos, fixando a sua posição: "ela é o processo pelo qual se estabelece a relação entre o mundo e as coisas” (p. 129). É um conhecimento prático que indica a posição do sujeito em relação a objetos, situações, eventos e a construção da realidade. Qualquer demanda de mudança dessas representações envolve alterações profundas em diversos níveis, seja do ponto de vista social, individual, relacional ou institucional (NASCIUTTI, 2006). Ou seja, não há um único ponto de partida e diferentes determinantes aparecem articulados para que se compreenda a complexidade da questão. 


\section{MÉTODO}

A abordagem utilizada na execução desse estudo foi de natureza qualitativa, considerada mais adequada para conhecer as representações sociais de um grupo específico e sua inserção num determinado contexto (BANCHS, 2002). Este formato de pesquisa evidencia respostas particulares, pois trabalha com o universo dos significados, dos processos e fenômenos que não são reduzidos à quantificação.

\section{Contexto da Pesquisa e Participantes}

A Pesquisa foi realizada no contexto das Políticas de Saúde e Assistência Social do município de Resende, localizado na Região do Médio Paraíba, sul do Estado do Rio de Janeiro, a 160 km da Capital, entre os principais centros do país: Rio de Janeiro, São Paulo e Belo Horizonte. A cidade possui uma população de 119.769 mil habitantes, com base em censo 2010 (IBGE, 2010) e conta com uma rede de equipamentos organizada para a operacionalização das políticas de cuidado ao usuário de álcool e outras drogas:

a) SAÚDE: 01 Centro de Atenção Psicossocial - CAPSII; 01 Centro de Atenção Psicossocial em Álcool e outras Drogas - CAPSAD; 01 Centro de atenção Psicossocial para Infância e Juventude - CAPSI; 01 Equipe de Consultório na Rua; 01 Equipe para ações de matriciamento na ESF; 01 Ambulatório ampliado descentralizado nas policlínicas; 10 Leitos no Serviço de Referência Hospitalar em Saúde Mental.

b) ASSISTÊNCIA SOCIAL: 04 Centros de Referência da Assistência Social - CRAS; 01 Centro de Referência da Assistência Social - CRAS Itinerante; 01 Centro de Referência Especializado da Assistência Social - CREAS; 01 Centro de Referência especializado para a População em Situação de Rua - Centro Pop; 01 Equipe de Abordagem Social; 01 República.

A escolha pelo município partiu de observações prévias em relação ao funcionamento da rede: a intersetorialidade na área é uma preocupação da gestão, mas ainda é pouco debatida; as iniciativas integradas entre as redes SUS e SUAS são incipientes e pouco utilizadas na prática cotidiana; há carência de estabelecimento de fluxos e protocolos em relação ao cuidado de usuários de substâncias psicoativas.

Por outro lado, alguns apontamentos realizados especificamente no CAPSAD indicaram que houve um crescimento populacional de usuários de substâncias psicoativas no município, refletido no quantitativo de procedimentos realizados. Além disso, há reincidência 
dos casos assistidos e simultaneidade de usuários atendidos em equipamentos da Saúde e da Assistência Social.

A escolha dos participantes foi por meio de uma amostra intencional que contemplou representantes de dispositivos de saúde que ofertam cuidado direto a usuários de álcool e outras drogas e de serviços socioassistenciais nos quais há maior integralidade dos mesmos.

A pesquisa contou com o total de 22 participantes, entre gestores e técnicos. Destes, 08 gestores das políticas de Saúde, Assistência Social e Conselho Municipal sobre Drogas. Os demais, 14 profissionais que atuam nos equipamentos das redes, contemplando membros de dispositivos citados anteriormente, com exceção do CAPSI que não enviou representante.

\section{Instrumentos}

Com os gestores municipais, optou-se por utilizar entrevistas semiestruturadas (MOURA; FERREIRA, 2005), para colher informações sobre a construção da política de drogas no município. Com os técnicos dos dispositivos foram realizados dois grupos focais com o objetivo de aprofundar aspectos relacionados à intersetorialidade na área de drogas.

O grupo focal é uma técnica coletiva, que permite que cada participante explicite seu ponto de vista diante da problemática sobre a qual foi convidado a falar. Esta técnica permite apreender sentimentos, atitudes, crenças, experiências e reações de uma maneira peculiar, o que não seria possível por meio com outros métodos. Para tanto, é necessário que todos tenham vivência com o tema em debate (GATTI, 2005).

\section{Aspectos Éticos}

O Projeto foi submetido à Plataforma Brasil e aprovado pelo Comitê de Ética em Pesquisa do Hospital de Clínicas de Porto Alegre (processo no 40593115.4.0000.5327). A pesquisa também foi autorizada pelas Secretarias de Saúde e Assistência Social do município. Todos os participantes assinaram o termo de consentimento livre esclarecido - TCLE.

\section{Coleta e Análise dos Dados}

Após a realização de um estudo piloto para identificar necessidade de eventuais ajustes nos roteiros dos instrumentos, foram realizadas as entrevistas semiestruturadas com 08 gestores das áreas de Saúde e Assistência Social do município, no intuito de conhecer a 
construção da política sobre drogas local. Com a equipe dos serviços, foram realizados dois grupos focais visando conhecer suas concepções sobre a intersetorialidade, os fatores que facilitam/dificultam a relação entre as áreas e identificar o potencial para ações conjuntas. O grupo da Assistência Social contou com a participação de 09 pessoas e o da Saúde com 05 pessoas. O conteúdo foi gravado em áudio e posteriormente transcrito.

$\mathrm{Na}$ primeira etapa de análise, foi realizada a codificação do material por meio da utilização do software NVIVO10 For Windows (QSR INTERNATIONAL, 2010). Essa ferramenta possibilitou estabelecer categorias que refletem as ideias mais significativas dos participantes agrupadas em "nós", que são uma forma de reunir e codificar o material em categorias de análise. Posteriormente, foi realizada a construção de indicadores qualitativos, a partir dos critérios de análise temática propostos por Braun e Clarck (2006). Para garantir confiabilidade aos achados, foi solicitada a análise das categorias por 05 profissionais especialistas, que possuíam a função de verificar a coerência das mesmas. Após os ajustes necessários, a análise temática foi realizada com o uso de vinhetas qualitativas para ilustrar cada representação.

\section{RESULTADOS E DISCUSSÃO}

No que se refere ao perfil dos gestores e da equipe técnica, que pode ser visualizado na Tabela 1, há uma predominância do sexo feminino e destaca-se que todos os profissionais de nível superior possuem pós-graduação.

TABELA 1 - Perfil dos Participantes

\begin{tabular}{|c|c|c|c|}
\hline & & Gestão & Equipe técnica \\
\hline \multirow[t]{2}{*}{ Sexo } & Feminino & 4 & 13 \\
\hline & Masculino & 4 & 1 \\
\hline \multirow[t]{3}{*}{ Escolaridade } & Nível médio & 0 & 7 \\
\hline & Graduação & 0 & 0 \\
\hline & Pós- Graduação & 8 & 7 \\
\hline \multirow[t]{3}{*}{ Faixa etária } & $30-40$ & 6 & 11 \\
\hline & $40-50$ & 0 & 3 \\
\hline & $50-60$ & 2 & 0 \\
\hline
\end{tabular}

FONTE: As autoras, pesquisa de campo. 
A partir da análise realizada com o NVIVO10, foram identificadas três grandes categorias temáticas. São elas: Papel da Intersetorialidade, Relação entre as Políticas e Potencial para Ações conjuntas:

QUADRO 1 - Categorias Temáticas

\begin{tabular}{l|l}
\hline Categoria Temática & \multicolumn{1}{c}{ Subcategoria } \\
\hline Papel da & - Complementaridade entre as políticas \\
Intersetorialidade & - Viabilizadora de direitos dos usuários \\
& - Fortalecimento do diálogo \\
\hline Relação entre as & - Relação de poder no compartilhamento de ações de saúde e assistência social \\
Políticas & - Entraves na prática cotidiana \\
& - Troca por meio de relações pessoais \\
\hline Potencial para ações & - Necessidade de construção de fluxos e protocolos \\
conjuntas & - Construção compartilhada para uma melhor eficácia das ações \\
& - Identificação com a área
\end{tabular}

FONTE: As autoras, pesquisa de campo.

\section{Representações sobre o papel da Intersetorialidade}

Essa categoria temática expressa as representações dos gestores e técnicos em relação ao papel a ser desempenhado pela intersetorialidade. A representação mais presente é que a atuação das Políticas de Saúde e Assistência Social deve ser complementar para resultados efetivos no cuidado aos usuários de álcool e outras drogas. O ponto de partida é que cada política pública possui uma função específica para com este usuário e a ausência, ou ineficácia de uma delas, pode dificultar o desenvolvimento da outra. Destaca-se que, para os profissionais da Assistência Social, esta barreira aparece como dificuldade em exercer a função da sua própria área. Muitas vezes, não conseguem concluir suas ações sem a inclusão de uma política complementar:

[...] na questão de álcool e drogas, nós não temos a competência de fazer uma intervenção mais profunda se a Saúde não estiver junto também.

[...] os desafios da Assistência são diversos, porque ela é uma política intersetorial. Sozinha ela não dá conta, a gente precisa dessa interface muito grande com a Saúde, com a Educação, com o Trabalho e Renda e, muitas vezes, não tem, porque essa crise que as políticas sociais vivenciam, elas vivenciam juntas.

Já para os profissionais da Saúde, também fica evidente a necessidade de articulação entre as duas políticas, para dar conta da complexidade de fatores envolvidos e demandados pelos usuários:

Serv. Soc. \& Saúde, Campinas, SP v.16, n. 2 (24), p. 189-210, jul./dez. 2017 E-ISSN 2446-5992 
[...] a intersetorialidade é fundamental. Sem ela é bem difícil fazer um trabalho de continuidade. Você está lidando com uma questão de múltiplos fatores. Existe uma questão de saúde, [...] social, existe uma questão familiar, uma questão em relação ao estigma, ao preconceito, ao mercado de trabalho, escolaridade. [...] Eu não vejo possibilidades de você fazer um acompanhamento de uma questão tão complexa, tão ampla, que atravessa tantas políticas sem, necessariamente, ter uma aproximação e uma articulação com a rede de serviços do município.

Identifica-se a necessidade de atuação conjunta para garantir a qualidade do atendimento aos usuários e suas demandas. Segundo Monnerat e Souza (2011), o conceito de intersetorialidade é voltado à construção de interface entre os setores, visando o enfrentamento de problemas sociais complexos que ultrapassam uma única política pública. Porém, como o município ainda não possui diretrizes específicas para ações intersetoriais, é preciso ter o cuidado de que a legislação pertinente à área em nível nacional não vire "letra morta". Como bem expõe Pereira e Teixeira (2013), frente à carência de uma orientação normativa pode vir a ocorrer um distanciamento entre o discurso intersetorial e o que acontece na esfera prática.

Neste sentido, outros estudos realizados junto à Rede de Saúde de municípios brasileiros evidenciaram que, apesar das práticas com usuários de drogas seguirem as diretrizes preconizadas pelas políticas nacionais, tais como a intersetorialidade e a integralidade do cuidado, existem fragilidades. Muitas vezes, há sobrecarga de trabalho nos serviços, as ações intersetoriais são pontuais e isoladas e há falta de suporte por parte da gestão municipal, o que pode vir a dificultar a articulação da rede, a aderência e a resolutividade dos casos. (SOUZA et al., 2012; COSTA et al., 2013).

A intersetorialidade também é vista enquanto viabilizadora do acesso dos usuários aos seus direitos, ou seja, como uma resposta eficaz às suas demandas. Assim, fica facilitada a identificação, pelos usuários, das funções de cada política setorial, acionando uma área ou outra de acordo com suas necessidades. Por exemplo, ter acesso à Saúde não exclui ser assistido pela Assistência SOCIAL, pois ambas são condição essencial para a garantia de seus direitos:

A gente trabalha para o usuário. Ele não tem que se reconhecer como usuário de um serviço só. Acho que o foco da intersetorialidade é isso, o ideal seria a gente trabalhar em conjunto, e ele sendo o usuário da assistência e da saúde ao mesmo tempo. 
Os profissionais de Saúde apontam a necessidade de um fortalecimento interno, pois muitos dos entraves que inviabilizam a garantia de direitos dos usuários perpassam o processo de trabalho nos dispositivos da própria política setorial:

Em relação a esse trabalho intersetorial, eu acho que a gente tem muito que crescer, trabalhar bastante em equipe, porque o único objetivo são os nossos usuários. Isso geralmente não acontece, nós esbarramos em vários entraves [...], seja para as questões internas de cada dispositivo, seja na questão da coordenação.

Destaca-se aqui a importância de visualizar o usuário como a principal finalidade da existência dos serviços e que relações intersetoriais fortalecidas podem facilitar o seu acesso às políticas públicas (RODRIGUES, 2011). Em relação ao consumo de drogas, analisar de que forma os profissionais se organizam e executam as ações de cuidado é imprescindível para que se evite compactuar com modelos fragmentados e excludentes de atenção, já que a abordagem do tema drogas abriga também um forte componente social (PAULA et al, 2004).

Segundo Ganev e Lima (2011) a reinserção é um direito social de caráter continuado, que se destaca como ponto norteador no trabalho junto a pessoas com problemas decorrentes do consumo de álcool e outras drogas. As graves consequências que podem levar à dependência de substâncias implicam na exposição dos usuários a diferentes situações de vulnerabilidade, inviabilizando e/ou afetando o desenvolvimento das suas potencialidades. Não há possibilidade de uma reinserção efetiva sem a atuação de políticas públicas de caráter multidisciplinar e interdisciplinar.

Identifica-se, ainda, a intersetorialidade como a troca de saberes entre os dispositivos para fortalecer o diálogo. Apesar dos segmentos de saúde e assistência apontarem que ocorrem intercâmbios, indicam a necessidade de um maior entrelace entre as equipes, não só no nível assistencial, mas também por meio de capacitações conjuntas e melhora na qualidade da comunicação:

É pra ampliar laços mesmo, facilitar o trâmite das questões. [...] ampliar esse contato através de seminários, de capacitação das equipes da assistência social e da saúde mental.

[...] é a comunicação entre dispositivos para que [...] a gente possa melhorar o nosso trabalho, estar sempre se ajudando, dar para cada um uma solução $[\ldots]$.

De fato, para a prestação de uma assistência adequada, a falta de espaço de aprendizado para trocas e diálogo pode ser um entrave para a resolução das demandas, pois a Serv. Soc. \& Saúde, Campinas, SP v.16, n. 2 (24), p. 189-210, jul./dez. 2017 E-ISSN 2446-5992 
complexidade do trabalho requer responsabilização e a construção de parcerias entre os setores (PAULA et al., 2004). No caso do município estudado, não se identificou no momento de realização da pesquisa experiências de capacitações conjuntas de equipes que atuam nas duas políticas setoriais. Neste sentido, apesar de existir uma parceria, ainda que incipiente, esta não alcança a resolutividade esperada ao se tratar de um trabalho conjunto entre políticas públicas.

A importância da construção deste espaço de aproximação é reforçada em estudo realizado por Souza et al. (2012), que recomenda como prioritário o treinamento de profissionais por meio de capacitações e reuniões de estudo. A valorização da equipe e a dedicação para qualificar os profissionais constituem políticas de gestão de recursos humanos consistentes com a proposta de horizontalização das relações. Todavia, Costa et al. (2013) alertam que programas de capacitação só trarão mudanças reais se forem articulados com outras ações sistemáticas e constantes, que impactem na mudança de práticas no cotidiano dos serviços.

\section{Representações sobre a Relação entre as Políticas}

Esta categoria temática exemplifica que relações estão sendo construídas no cotidiano dos serviços e como os atores envolvidos as representam. O destaque é a relação de poder existente entre as políticas, ou seja, no compartilhamento de ações entre a saúde e a assistência social. Para a equipe da Assistência Social, há a percepção de que os técnicos de sua área apresentam uma fragilidade em sua atuação, em virtude da desvalorização da Saúde em relação às avaliações dos casos por eles realizadas. Destacam que o profissional da Assistência Social pode ter a mesma formação que o da Saúde e a mesma competência. Mas, segundo os participantes, esta avaliação não é respeitada pelos "especialistas", ou seja, os profissionais que atuam nas unidades de saúde de referência para esse público:

[...] tem vários fatores que influenciam esse atendimento entre setores, a questão da porta de entrada. Obviamente, a de álcool e drogas é na área de saúde, mas [...] o atendimento do profissional da Assistência fica muito desqualificado [...]. A última palavra vai ser daquele profissional da área de Saúde. Eu vejo muito essa desqualificação da Saúde em relação ao mesmo profissional [...], de não levar em consideração [...]: 'eu tenho a palavra final, eu sou desse serviço específico'. Eu vejo relação de poder mesmo.

[...] ficam muitos rótulos, tipo assim: 'ah você trabalha na área da Assistência, você entende só de social'. Mas, espera aí, eu sou psicóloga. E

Serv. Soc. \& Saúde, Campinas, SP v.16, n. 2 (24), p. 189-210, jul./dez. 2017 E-ISSN 2446-5992 
chegando lá, por exemplo, num CAPS, conversando com outra psicóloga, eu também tenho um olhar da mesma forma que ela tem, independente de eu estar na Saúde ou na Assistência. [...] Esse olhar tem que ser considerado, independentemente de onde você está atuando.

Fica evidente a relação de poder estabelecida pela Saúde sobre a Assistência Social, onde os executores da assistência acabam por reproduzir este movimento, uma vez que, deixam de encaminhar os usuários ou os encaminham sem a certeza de que seu parecer será levado em consideração. A relação pode ficar "travada" por desconhecimento sobre a função da Assistência Social nas ações de cuidado. Em alguns relatos, apareceu a visão de que os profissionais da Saúde acreditam que as equipes da Assistência Social devem atender somente vulnerabilidades.

Este achado está de acordo com a literatura, que aponta que o setor Saúde destaca-se como liderança em relação aos demais setores sociais. Porém, a Organização Pan-Americana da Saúde recomenda que a Saúde deva ter, não somente iniciativa para propor a ação intersetorial, mas também receptividade à convocatória de outros setores (MONNERAT; SOUZA, 2011; PAULA et al., 2004). O esforço setorial isolado da Saúde não conseguirá dar conta da questão do uso de substâncias, pois o tema remete a diversas causas e dimensões (COSTA et al., 2013).

São referidos, ainda, pelos profissionais da Assistência Social, entraves na prática cotidiana, com destaque para a divergência em relação ao acompanhamento dos casos:

Já contatamos diversas vezes a Saúde Mental, a gente não teve retorno. [...] O que a Saúde Mental diz é 'a gente não faz busca ativa'. Mas, como vocês não pensam numa ação de busca ativa, numa ação em conjunto? [...] A gente está amarrado, porque o que competia à Assistência a gente já chegou ao limite; a gente não consegue fazer esse acompanhamento familiar, sem que eles estejam sendo acompanhados nos dispositivos que vão tratar a questão do uso e do abuso de álcool e outras drogas. Mas esses dispositivos, não posso dizer não assumem esta responsabilidade, mas não estão juntos. É bem complexo.

A Saúde refere entraves no seu próprio processo de trabalho, dificuldades entre "os egos" profissionais e a necessidade de fortalecimento de um conceito de equipe:

Na realidade é uma visão egocêntrica, cada um olha pro seu umbigo, não vê que o usuário é da rede. Então assim, 'eu não vou emprestar porque ele numa época não emprestou', e o carro é da Saúde Mental. É palhaçada, porque se é da prefeitura, se é da Saúde Mental, se é pro bem estar do usuário, então logo todo mundo vai pensar na mesma causa, todo mundo vai andar, vai ser feliz. 
Pras coisas andarem, fluírem, você se sentir bem no ambiente de trabalho; tem que ter união, desde a coordenação até quem limpa, quem faz a comida, acho que tem que ter esse diálogo, essa união entre eles, independente de quem for. Porque muitas coisas não acontecem sem o diálogo, vai ficar sempre assim, sempre andando pra trás... um passo pra frente, dez pra trás.

Os profissionais de Saúde visualizam a relação de interdependência entre as políticas como uma via de mão dupla que, em alguns momentos, se encontra enrijecida. Acreditam que é em virtude de um desconhecimento das funções, pois ainda existe confusão de papéis e falta uma direção única de trabalho na área:

A parceria existe sim, em alguns momentos enrijecida, em alguns momentos ela funciona; mas acho que a gente devia trabalhar mais em uma direção única. Não estou dizendo que a gente devia todos pensar igual [...]. Que bom que cada um traga uma ideia diferente, isso nos faz crescer, mas temos que ter uma direção, um objetivo final, que é o usuário. Em alguns momentos eu vejo que o profissional quer, mas fica ali, travado.

Se uma é braço, outra é perna, outra é corpo. Acho que se todo mundo tem uma visão do usuário, que é quem precisa da gente, do nosso socorro, da ajuda, as coisas funcionam. Mas se você entra em competição não adianta nada, a gente não vai chegar a lugar nenhum. Vai sofrer o usuário, vai sofrer a gente [...]. Nessa competição, acho que tem que ter outra visão: um depende do outro.

Lidar com as consequências da dependência de drogas não é tarefa fácil e estas vinhetas destacam dificuldades presentes para a efetivação da intersetorialidade no município. Todavia, a necessidade da reinserção social deve estar no foco das ações desde o primeiro atendimento, independente de qual foi a "porta de entrada" do usuário no Sistema de Proteção Social (GANEV; LIMA, 2011).

Neste sentido, percebe-se que a relação que ainda não está estabelecida de modo

institucional fica no nível pessoal, ou seja, personificada nos indivíduos que atuam na execução da política:

Hoje cada um tem relações pessoais. Assim, você conhece fulaninho, o técnico trabalha na Saúde Mental, aí, por vocês serem amigos, vocês se ligam. Aí a pessoa fica com uma implicação pessoal de te dar um retorno, não uma implicação enquanto instituição, mas enquanto pessoa. Enquanto eu estou ali e ele também, aí beleza, né, o negócio vai andar, no momento que não tem fluxo, não tem protocolo.

Tem alguns avanços, com os usuários que estão no CAPS, é muito mais essa implicação pessoal com o próprio profissional, eu falo isso tanto da Saúde quanto da Assistência. Eu, por exemplo, tenho dificuldade com alguns profissionais de estar avançando naquele usuário que é referência de algum profissional, e outros a gente avança mais porque tem uma relação de

Serv. Soc. \& Saúde, Campinas, SP v.16, n. 2 (24), p. 189-210, jul./dez. 2017 E-ISSN 2446-5992 
empatia. Mas é sempre pela proposta de estar [...] cobrando dos próprios equipamentos esses atendimentos essa intersetorialidade [...]. Isso hoje fica muito nessas relações pessoais.

É nítida a representação de que a relação intersubjetiva (face a face) é um fator facilitador para a implementação da intersetorialidade quando há uma implicação pessoal do profissional. Todavia, fica evidente a necessidade de padrões institucionalizados para uma melhor efetivação das ações conjuntas. Conforme apontam Ganev e Lima (2011), é preciso aprimorar a oferta das políticas públicas por meio de qualificação e estruturação dos serviços.

\section{Representações sobre Potencial para ação conjunta}

Esta categoria diz respeito à representação em relação ao futuro, o que os profissionais acreditam que deva ser feito para uma melhor assistência aos usuários. O primeiro ponto é a necessidade de maior sistematização dos dados, por meio da construção de fluxos e protocolos, pois uma dificuldade enfrentada é a grande rotatividade de profissionais inseridos nas equipes:

[...] encaminhando esse sujeito, mesmo quando ele chega no meu equipamento, de estar formalizando isso e colocando um documento, formulário de encaminhamento e atrás a contrarreferência e cobrando desse profissional que está atendendo lá. Se ele der o retorno, que ele escreva qual tipo de atendimento, qual tipo de encaminhamento que ele deu, e acompanhar esse usuário posteriormente. Aí que eu falo que é o grande desafio.

[...] mas se você não conhece ninguém, não tem nomes ou mudou a equipe, o negócio para, não flui; e aí a questão do protocolo é importante também, por conta das atividades políticas da assistência, quanto da saúde. Às vezes você perde caso, por mais que ele esteja sendo acompanhado, porque eles não sabem exatamente qual é o técnico de referência. Aquela pessoa que tinha todo um conhecimento, todo o acompanhamento saiu, e a outra vai ter que pegar tudo do início, e isso demora um tempo bom.

Destaca-se a possibilidade de melhora das relações através do ajustamento entre as equipes. Na percepção dos profissionais da assistência social, há dificuldades nos encaminhamentos que carecem de dados consistentes, sem a história de vida desse sujeito, e a sistematização referida poderia auxiliar na construção de uma prática compartilhada.

Para isto, é preciso fortalecer mecanismos de comunicação e fluxos de informações, pois são aspectos cruciais para ultrapassar as barreiras e concretizar as práticas intersetoriais (MONNERAT; SOUZA, 2011). Outro ponto é valorizar o planejamento estratégico que 
envolva representantes de diferentes setores, pois ele incentiva a visão crítica e permite a organização do sistema de referência e contrarreferência à luz de diferentes práticas. Assim, poderá ser organizada uma importante base para a manutenção do atendimento intersetorial e integral no município (SOUZA et al., 2012).

\section{É necessária também a construção compartilhada para uma melhor eficácia das}

ações, pois a clínica de álcool e drogas é complexa e não dá conta sozinha das demandas, precisa de um suporte das outras políticas setoriais. Para a assistência social, esse público é afetado em vários aspectos da vida e existe a necessidade de trabalhar em conjunto:

O uso abusivo do álcool e da droga ele vai 'esgaçar' todas as outras relações, as relações familiares, as relações de trabalho, vai colocar esse indivíduo em risco. Se a gente consegue realmente sentar e pensar em ações estratégicas em conjunto e que tenham um impacto, sairão coisas muito maiores.

Ele [o usuário] vai conversar comigo no CREAS, vai conversar com um técnico da Saúde Mental e falar tudo de novo. Quando ele chegar lá, ele não vai falar. [...] Se for fazer alguma coisa, tem que fazer de forma articulada [...], vamos pegar alguém da Saúde Mental e alguém da Assistência. Porque é isso, as demandas se atravessam, se a gente não consegue enxergar [...], vai ser um indivíduo que aqui vai tratar a questão da violência, no outro vai tratar a questão o álcool e drogas.

Para a saúde, o propósito é pensar o indivíduo em sua totalidade e não focar apenas na patologia que se apresenta:

Na questão droga, eu acho que ampliar [...] esse conceito dentro da própria saúde, e poder conversar mais e definir mais papéis, políticas e dispositivos que trabalhem a necessidade dos usuários em contextos diferentes: o que é do contexto social, do familiar, do estrutural, da questão de trabalho [...]. O que acaba levando a pessoa ao consumo abusivo de substâncias, muitas vezes é desencadeado por outros fatores [...]. Poder trabalhar caso a caso e ver de que forma cada área [...] pode colaborar de forma integral, integrada, sem ter que transferir esse usuário pra um ou outro lugar.

O maior desafio pra entender que uma pessoa pode estar sendo acolhida num dispositivo de Assistência, pode estar fazendo um acompanhamento num dispositivo da saúde mental, um acompanhamento num especialista de uma questão que não diga respeito a álcool e drogas [...], sem que tenha que ser transferida para outro lugar pelo fato de ser usuária. Que ela possa ter acesso às políticas de saúde e de assistência sem essa questão do preconceito, do estigma, do rótulo [...]. A questão do uso não pode ser o que define, ela precisa ser cuidada, um sujeito não pode ser definido pela substância que ele usa. Todas as áreas precisam ampliar o conceito em questão do álcool e drogas e não limitar o sujeito [...], porque aí a articulação vai ficar comprometida [...]. Se não houver essa compreensão de sujeito como um todo, esses dispositivos também vão ser limitados.

Serv. Soc. \& Saúde, Campinas, SP v.16, n. 2 (24), p. 189-210, jul./dez. 2017 E-ISSN 2446-5992 
Novamente aparece a importância do trabalho em conjunto, focando aspectos que vão do individual às implicações em diferentes áreas que podem afetar a vida do sujeito. $\mathrm{O}$ objetivo é inclusão e reinserção social, e a dependência de drogas é vista como resultante do encontro de uma pessoa com uma droga em um dado momento sociocultural, numa tríade indivíduo-droga-contexto (Teixeira et al., 2017).

Um estudo realizado em dois CAPS-AD com o objetivo de conhecer a percepção de usuários, acompanhantes e profissionais acerca do modelo de atenção à saúde de usuários de drogas, mostrou que estes atores percebem a importância dos elementos que compõem a política definida pelo Ministério da Saúde (intersetorialidade, formação da rede comunitária). Porém, ficou evidente que há grande dificuldade de atender esses princípios na vivência cotidiana (MORAES, 2008).

Sustenta-se aqui a importância das instituições estarem em constante movimento de interrogação, compreendendo sua produção como um processo histórico e social, que exige transformações no modo de organização dos serviços e a construção da equipe como um coletivo que reúne diferentes saberes. Assim, evita-se a simples reprodução das relações de poder e a cristalização das ações, contribuindo para o "fechamento das portas", ao invés de sua abertura para novas possibilidades de atuação (SOUZA et al., 2012; NICÁCIO; CAMPOS, 2005).

Ao projetar possíveis ações, emergiram representações relacionadas à identificação com a área, ou seja, a importância do profissional ter o desejo de atuar na política que está inserido, para garantir a qualidade da assistência prestada:

[...] de preconceito, de estar atuando até na própria política, às vezes tem profissional que não gosta de atender certos usuários [...]. Mas, eu vejo muito do vínculo desse profissional com o equipamento, e passa por um vínculo de ético a político, enfim, que está realmente implicado naquele tipo de demanda que está atendendo.

Para uma boa atuação, foi unânime a necessidade da melhora na motivação dos profissionais, que devem estar comprometidos com a própria prática e acreditar no potencial do trabalho que realizam. Em consonância, Schutz e Mioto (2010) defendem que além da vontade política dos dirigentes, é necessária a sensibilização dos servidores públicos para as mudanças, e sua valorização enquanto trabalhadores para a adoção de uma lógica intersetorial. 
Além disso, apenas focar na ampliação da rede de serviços não é suficiente. É preciso investir em uma formação profissional adequada, que incentive os profissionais a sintonizarem com os princípios da humanização e da atenção psicossocial, dispondo-os a romper com as lógicas excludentes dos sujeitos que fazem uso de substâncias psicoativas, tão enraizadas em nossa sociedade (MORAES, 2008; COSTA et al., 2013). Assim, a intersetorialidade não implica a exclusão da perspectiva setorial (LAPORT; JUNQUEIRA, 2015), mas sim, a integração de ações visando superar a fragmentação e a desarticulação das políticas públicas, a partir do investimento em seu capital humano.

\section{CONCLUSÃO}

Em anos recentes, a intersetorialidade tem se destacado em diversas áreas do conhecimento como uma peça chave para melhorar a execução de políticas públicas e, gradativamente, vem sendo incorporada às práticas institucionais. Apesar disto, é nítido que este assunto ainda é pouco debatido, apresentando certa dificuldade de conceituação por parte dos profissionais.

No campo de álcool e outras drogas, a intersetorialidade representou uma mudança de paradigma, na medida em que, historicamente, as políticas eram excludentes e abordavam o problema como sendo de responsabilidade exclusiva de um determinado setor, seja a Saúde ou a Segurança Pública. Neste sentido, a construção das atuais políticas sobre drogas brasileiras foi um marco importante, ao prever ações de atenção psicossocial intersetoriais de base comunitária, tanto no Sistema Único de Saúde quanto no Sistema Único de Assistência Social.

A realização deste estudo permitiu problematizar a construção prática de representações sobre a intersetorialidade, compreendendo de que forma o conceito se concretiza no trabalho diário em equipamentos públicos voltados à população com problemas decorrentes do consumo de substâncias psicoativas. A despeito dos dados aqui apresentados não poderem ser generalizados por tratar-se de uma pesquisa qualitativa, observou-se que corroboram entraves já detectados na literatura. Há muitos desafios a serem enfrentados pelos profissionais, e um longo caminho a ser percorrido para que as diretrizes teóricas se traduzam em novas práticas, garantindo a melhora na qualidade do atendimento prestado, a saber:

- Embora o tema seja atual e, enquanto diretriz, já esteja inserido nas Políticas de Saúde, Assistência Social e na Política Municipal de Álcool e Outras 
Drogas, as ações intersetoriais enquanto recurso são pouco utilizadas na prática profissional cotidiana do município.

- A dificuldade de conceituação da intersetorialidade por parte da equipe técnica pode refletir na não efetivação, em sua plenitude, de possíveis ações intersetoriais entre as políticas de saúde e assistência social.

- Os entraves existentes para a integração e planejamento das ações assistenciais, muitas vezes, geram tensões entre as equipes, ou até dentro de um mesmo dispositivo.

- Falta o estabelecimento de fluxos e protocolos que institucionalizem a atuação junto a usuários de substâncias psicoativas, para além das ações individuais de cada profissional.

- A sensação de desprestígio por parte da Saúde, apontada pelos profissionais da Assistência Social no que se refere a sua prática profissional, é um dos maiores entraves para a atuação intersetorial das equipes, mostrando uma relação de poder assimétrica entre as duas políticas.

Diante deste quadro desafiador, há urgência no fomento de espaços de trocas e diálogo, para que ambas as áreas possam aprender uma com a outra e compartilhar experiências. Neste sentido, a oferta de capacitações conjuntas poderá fortalecer as relações, contribuindo para a construção de uma melhor atuação. Destaca-se que o setor Saúde, ainda muito inserido em seu próprio processo de trabalho, possa investir mais no olhar integral, integrando a seu cotidiano possibilidades trazidas por outras políticas no cuidado aos usuários.

Apesar de todos os entraves encontrados, é importante considerar que os profissionais inseridos nas duas políticas referem o desejo de realizar a intersetorialidade de forma mais plena, o que aponta para uma possibilidade de estreitamento do diálogo e um possível estabelecimento de fluxos. O fato do município já estar expandindo as ações na área de álcool e outras drogas a partir de uma rede bem estruturada em nível local é um ponto positivo, que demonstra o esforço para minimizar a lógica setorial fragmentada. Assume-se, assim, que este investimento poderá refletir na melhora do acesso dos usuários aos serviços, tendo em vista que os próprios profissionais apontaram que o usuário é o principal protagonista e objetivo final de todo o trabalho que realizam. 
Espera-se, a partir da consecução deste estudo, contribuir na melhoria da qualidade da assistência prestada à população do município, além do fortalecimento das políticas públicas sobre drogas e o avanço nas construções teóricas sobre o tema da intersetorialidade no Brasil.

Recebido em 26.07.2017 - Aprovado em 26.12.2017

\section{REFERÊNCIAS}

ANDRADE, A. G. (Orgs.) Práticas integrativas na aplicação da Lei n 11.343/06 - Lei de

Drogas. $1^{\text {a }}$. ed. Brasília: Ministério da Justiça - Secretaria Nacional de Políticas sobre Drogas, 2014. v. 1. 160p .

BANCHS, M. A. Representaciones sociales y subjetividad. IN: O. FURTADO; F. L. GONZÁLES REY (Orgs). Por uma Epistemologia da Subjetividade: um debate entre a teoria sócio-histórica e a teoria das representações sociais. São Paulo: Casa do Psicólogo, 2002, pp. 43-64.

BOSCHETTI, I. Assistência social no Brasil: um direito entre a originalidade e conservadorismo. 2 ed. Brasília, 2003.

BRASIL. Lei n⿳11343/2006, de 23 de agosto de 2006. Institui o Sistema Nacional de Políticas Públicas sobre Drogas - SISNAD; prescreve medidas para prevenção do uso indevido, atenção e reinserção social de usuários e dependentes de drogas; estabelece normas para repressão à produção não autorizada e ao tráfico ilícito de drogas; define crimes e dá outras providências, 2006.

BRASIL. Legislação e Políticas Públicas sobre Drogas. Brasília, Presidência da República, Secretaria Nacional de Políticas sobre Drogas, 106p, 2010.

BRAUN, V.; CLARK, V. Using thematic analysis in psychology.Qualitative Research in Psychology, 2006 3(2) (P. 77-101). Disponível em:

http://eprints.uwe.ac.uk/11735/2/thematic_analysis_revised_-_final.pdf. Acesso em: 29 jun 2017.

COSTA, P. H. A.; MOTA, D. C. B.; CRUVINEL, E; PAIVA, F. S.; RONZANI, T. M.

Metodologia de implementação de práticas preventivas ao uso de drogas na atenção primária latino-americana. Rev Panam Salud Publica. 2013;33(5):325-31. Disponível em: http://www.scielosp.org/pdf/rpsp/v33n5/a03v33n5.pdf. Acesso em 26 jun 2017. GANEV, E.; LIMA, W. L. Reinserção social: processo que implica continuidade e cooperação. Serviço Social \& Saúde, Campinas, v. 10, n. 11, p. 113-129, 2011. Serv. Soc. \& Saúde, Campinas, SP v.16, n. 2 (24), p. 189-210, jul./dez. 2017 E-ISSN 2446-5992 
GATTI, B.A. Grupo focal na pesquisa em ciências sociais e humanas - Brasília: líber livro editora, 2005.

INSTITUTO BRASILEIRO DE GEOGRAFIA E ESTATÍSTICA (IBGE). Censo de 2010. Instituto Brasileiro de Geografia e Estatística, 2010.

JUNQUEIRA, L. A. P. A gestão intersetorial das políticas sociais e o terceiro setor. Saúde e Sociedade, São Paulo, v. 13, n. 1, p. 25-36, Apr. 2004. Disponível em:

http://www.scielo.br/scielo.php?script=sci_arttext\&pid=S0104-12902004000100004. Acesso em 4 jul 2017.

JUNQUEIRA, L. A. P. Intersetorialidade, transetorialidade e redes sociais na saúde. Revista de Administração Pública, Rio de Janeiro. nov/dez.2000; v. 34, n. 6,p.35-45.

LAPORT, T. J.; JUNQUEIRA, L.A.P. A Intersetorialidade nas Políticas Públicas sobre Drogas. In: RONZANI, T. M.; COSTA, P. H. A.; MOTA, D.C.B.; LAPORT, T. J. (Orgs.) Redes de Atenção aos Usuários de Drogas: políticas e práticas. São Paulo: Cortez, 2015. p. 67-84.

MONNERAT, G. L.; SOUZA, R. G. Da seguridade social à intersetorialidade: reflexões sobre a integração de políticas sociais no Brasil. R. Katálysis, v.14, nº 1, jan /jun 2011. Disponível em: http://www.scielo.br/scielo.php?script=sci_arttext\&pid=S141449802011000100005. Acesso em 4 jul 2017.

MORAES, M. O modelo de atenção integral à saúde para tratamento de problemas decorrentes do uso de álcool e outras drogas: percepções de usuários, acompanhantes e profissionais. Ciência \& Saúde Coletiva, 13(1):121-133, 2008. Disponível em: http://www.scielo.br/scielo.php?script=sci_arttext\&pid=S1413-81232008000100017. Acesso em 26 jun 2017.

MOTA, D. C. B.; MOREIRA, R .B. S.; LAPORT, T. J. O desafio da intersetorialidade na área de drogas. In: RONZANI, T.M. (Org). Ações integradas sobre drogas prevenção, abordagem, e políticas púbicas. Juiz de Fora: editora UFJF, 2013, p. 387 - 427 MOTA, D. C. B.; RONZANI,T.M. Implementação de políticas públicas brasileiras para usuários de álcool e outras drogas. In: RONZANI, T.M. (Org). Ações integradas sobre drogas prevenção, abordagem, e políticas púbicas. Juiz de Fora: editora UFJF, 2013. p. 293-324

MOURA, M. L. S.; FERREIRA, M. C. Projetos de Pesquisa elaboração redação e apresentação. Rio de Janeiro: EDUERJ, 2005. 
MOSCOVICI, S. Representações sociais: investigações em psicologia social. Rio de Janeiro: Vozes. 2003.

NASCIUTTI, J. C. R. A Instituição como Via de Acesso à Comunidade. In: FREITAS CAMPOS, R. H. (org.). Psicologia Social Comunitária: da solidariedade à autonomia. Petrópolis - RJ: Editora Vozes, 2006, 11ª edição, p. 100-126.

NICÁCIO, F.; CAMPOS, G. W. S. Instituições de "portas abertas": novas relações usuáriosequipes-contextos na atenção em Saúde Mental de base comunitária/territorial. Revista de Terapia Ocupacional. Univ. São Paulo, v. 16, n. 1, p. 40-46, jan./abr., 2005. Disponível em: http://www.revistas.usp.br/rto/article/view/13957. Acesso em 26 jun 2017.

OLIVEIRA, M. S. B. S. Representações sociais e sociedades: a contribuição de Serge Moscovici. Revista Brasileira de Ciências Sociais, jun. 2004; vol.19, n 55, p.180-186 PAULA, K.; PALHA, P.; PROTTI, S. Intersetorialidade: uma vivência prática ou um desafio a ser conquistado?O discurso do sujeito coletivo dos enfermeiros nos núcleos de saúde da família do Distrito Oeste - Ribeirão Preto. Interface - comunic, Saúde, Educação, v. 8 n.15, p. 331-348 mar./ago. 2004.

PEREIRA, K. Y. L.; TEIXEIRA, S. M. Redes e intersetorialidade nas políticas sociais: reflexões sobre sua concepção na política de assistência social. Textos \& Contextos, Porto Alegre, jan./jun. 2013; v. 12, n. 1, p. 114 - 127

QSR INTERNATIONAL. Manual NVIVO10 For Windows. QSR International, 2010 RODRIGUES J. A intersetorialidade entre as políticas públicas de saúde e de assistência social pós Constituição Brasileira de 1988. V Jornada Internacional de Políticas Públicas, 23 a 26 de agosto, 2011.

ROMAGNOLI, R. C. Entre a Educação e a Saúde: o desafio das redes. Pesquisas e Práticas Psicossociais, 2010. 4(2) P. $182-192$.

SARONI, H.; GOMES, K.V.; SILVA, S. M. L.; Severino, V. C.; Santos, F. R. A Construção das Políticas Públicas Intersetoriais em Álcool e Outras Drogas: a experiência do município de Guarulhos. Anais do IV Seminário Internacional de Integração Étnico-Racial e as Metas do Milênio, 2016, Vol. 3, Nº1, 150-158.

SCHUTZ, F; MIOTO, R. C. T. Intersetorialidade e política social: subsídios para o debate. Sociedade em Debate. 2010; 16(1), p. 59. Disponível em: http://www.rle.ucpel.tche.br/index.php/rsd/article/view/337 Accesso em 17 Jul 2017. SÊGA, R. A. O conceito de representação social nas obras de Denise Jodelet e Serge Moscovici. Anos 90. Porto alegre, jul. 2000, n.13, p.128-133. 
SOUZA, J.; KANTORSKI, L. P.; VILLAR LUIS, M. A.;OLIVEIRA,N. F. Mental health interventions to treatment of drugs' abusers patients: policies, practices and documentation. Texto contexto - enferm. Florianópolis , v. 21, n. 4, p. 729-738, Dec. 2012. Disponível em: <http://www.scielo.br/scielo.php?script=sci_arttext\&pid= S0104-07072012000400002\&lng=en\&nrm=iso>. Accesso em 17 Jul 2017. TEIXEIRA, M. B.; RAMOA, M. L.; ENGSTROM, E.; RIBEIRO, J. M. Tensões paradigmáticas nas políticas públicas sobre drogas: análise da legislação brasileira no período de 2000 a 2016. Ciência e Saúde Coletiva, Rio de Janeiro, v. 22, n. 5, p. 1455-1466, May 2017. Disponível em: http://www.scielosp.org/scielo.php?script=sci_arttext\&pid=S1413-

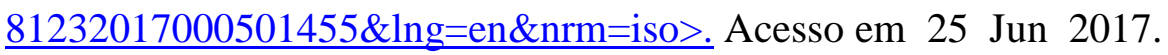
UNITED NATIONS OFFICE ON DRUGS AND CRIME - UNODC. World Drug Report: executive summary. Vienna: United Nations publication, 2016. 